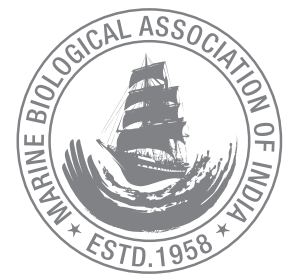

\title{
Potential Yield Estimates for marine fisheries of Gujarat
}

\author{
Vinaya Kumar Vase*, K. Rajan, J. Jayasankar', K. R. Sreenath', Koya K. Mohammed', D. Divu \\ and Prathibha Rohit ${ }^{2}$ \\ Veraval Regional Center of ICAR - Central Marine Fisheries Research Institute, Veraval-362 269, Gujarat, India. \\ IICAR-Central Marine Fisheries Research Institute, Kochi-682 018, Kerala, India. \\ ${ }^{2}$ Mangalore Research Center of ICAR - Central Marine Fisheries Research Institute, Mangalore-575 001, Karnataka, India. \\ *Correspondence e-mail: v.vinaykumarvs@gmail.com
}

Received: 10 Dec 2019 Accepted: 25 Dec 2019 Published: 30 Dec 2019

Original Article

\begin{abstract}
Gujarat is the leading maritime State in marine capture fisheries in the country with current (2018) contribution of 7.80 lakh tonnes. The landings and fishing effort spent has escalated by $46.34 \%$ and $25.46 \%$ respectively since 1994 . The study estimated the potential yield (maximum sustainable yield) for the 24 resource groups by using catch and standardized effort (a modified version) as input into the surplus production model. The current fish catch to potential yield ratio ( $\left.Y_{\text {cur }} / M S Y\right)$ was found to be in the range of 0.25-1.54 for the groups, with maximum fishing pressure experienced by silverbellies. The overall potential yield estimated for the State was 9.20 lakh tonnes plus, which is higher than the present catch of 7.80 lakh tonnes. The current situation offers an opportunity to further increase the catch with an increased effort by reducing the fishing pressure in territorial waters. However, fishing effort can be raised for the underexploited large pelagic resources like tuna, seerfish, barracudas, large carangids, etc., which are captured mainly by large mesh gillnet or long lines in the region. The study also recommends more in-depth investigations on the catch by different fishing gear at species level estimation of the potential yield and validation of the same using alternate approaches.
\end{abstract}

Keywords: Catch, standardized effort, Ycurr/MSY, median catch

\section{Introduction}

India is a leading nation in the Indian Ocean region in marine fish harvest from the wild, harvesting an estimated 3.49 million tonnes (FAO, 2018; CMFRI, 2019). The fishery production from the wild, in general, has increased over the years owing to the advancement in terms of number, power and endurance of the fishing fleet, duration of fishing voyage and improved processing and supply chain for the fishery products. The state of Gujarat, along the west coast of India, witnessed remarkable development in the marine capture fisheries sector. The State is naturally gifted with abundant marine fishery resources, $1600 \mathrm{~km}$ long coastline, 2 lakh $\mathrm{km}^{2}$ of the exclusive economic zone and a shelf area of 1.64 lakh $\mathrm{km}^{2}$. The abundance of easily accessible fishery resources, together with the strong fishing fleet of 28,400 (DAHDF and CMFRI, 2012), dominated by multi-day trawlers has allowed the State to surpass all other maritime states of the country in recent years in the marine capture fisheries production. The present contribution of the State to national marine capture fisheries basket is 7.80 lakh tonnes ( $22.4 \%$ of the total). An increase of catch is not always the indicator of healthy or sustainable development, especially when the fishing efforts are on an exponential rise. Gujarat has witnessed a rapid increase in the mechanized trawl fleet, which has increased from 1,410 in 1980 to 8,002 and 11,582 in 2005 and 2010, respectively (CMFRI, 
1981; DAHDF and CMFRI, 2006, 2012). The fishing capacity of the individual vessel has been strengthened with upgradation in size and engine capacity. The handling/processing capacity of the mushrooming seafood industry in the State has also kept pace with the increase in landings over the year.

All these developmental activities have contributed substantially to the seafood sector of the State. Still, some questions of concern that need to be addressed at the earliest are sustainability, optimum level of exploitation, optimum fleet strength, etc. A long term (how many years?) scientific investigation of catch dynamics is required to answer the above concerns posed in the marine capture fisheries of the State. The estimation of potential yield in comparison with the present landing could give an insight into the health of the fishery of the State and form a basis for the sustainable management of the available marine fishery resources. Earlier studies (Prasad et al., 1970; Jones and Banerji, 1973; Mitra, 1973) estimated the fishery potential of the Indian Ocean based on primary productivity and catch trends. Besides, several attempts have been made by working groups to assess the potential yield of marine fisheries from the Indian Exclusive Economic Zone (EEZ) with the latest being in 2011. Whereas the estimations were made using multiple approaches, viz, a) yield based-tropho-dynamic based model (DAHDF, 2011), b) Holistic models-where a stock is considered as a pool of biomass, which is relatively simpler compared to analytical models as they do not require details on age and length composition (cohort-based), c) The surplus production models which require time-series data on the total yield from the stock and effort spent for the same and forms the ideal method to arrive at maximum yield that can be sustained without compromising long term productivity, ie., Maximum Sustainable Yield (Sparre and Venema, 1998). The potential yield estimation using the Surplus production model either in linear or non-linear form has been applied to several fisheries from the Indian EEZ (Balan and Sathianandan, 2007; Sathianandan et al., 2008; Sathianandan and Jayasankar, 2009; Najmudeen et al., 2014; Sreekanth et al., 2015) and provide management advisories in terms of regulating or optimizing fishing effort to sustain resources. In this view, the present study aims at applying Schaefer's surplus production models to the time series catch and effort data of Gujarat across the commercially important groups to work out the potential yield for the same. The estimated potential yield is comparable with a recent catch to assess the health of a given stock. The cohortbased study forms the baseline for the resources which show signs of overfishing and catch optimization through regulation of fishing effort in the region.

\section{Material and methods}

The fishery resources landed in the State were categorized into 24 groups for the present study. The data on gear wise catch and effort was taken from the National Marine Living Resources Data Centre (NMLRDC) of the ICAR-Central Marine Fisheries Research Institute, Kochi, for the period 1994-2017. Catch and effort data were used to arrive at catch per unit effort (CPUE). Generally, in a tropical fisheries scenario like ours where multiple species groups are caught in one gear and one group is caught by several gears simultaneously, the usage of catch and effort (in hours) as input in holistic models may not produce better results. A resource group-specific standardized effort would be a better input than the common fishing effort. The standardization process of fishing effort used in the present work has been illustrated below (Varghese et al., 2020).

\section{Results}

The annual catch for the various species group did not show similar patterns in increase or decrease. Rather, they showed a distinct growth pattern over the years. A heat map indicating time-series variations in the catch of resource groups are presented in Fig. 1. A notable increase was observed in the landings of resources like ribbonfishes, perches, crustaceans, cephalopods. The decline was evident in landings of conventional resources like croakers, whereas fluctuation was witnessed in the case of bombayduck. The average percentage contribution (for 24 years) of an individual species group varied from 0.014 to $21.037 \%$. Resources like bigjawed jumper $(0.107 \%)$, barracudas $(0.338 \%)$, billfishes $(0.105 \%)$, eels $(0.562 \%)$, halfbeaks and fullbeaks $(0.053 \%)$, silverbellies $(0.138 \%)$ and unicorn cod $(0.014 \%)$ contributed less than $1 \%$ of the total landings of the state. In contrast, resources like crustaceans (21.037\%), ribbonfishes (11.251\%), croakers (10.885\%) and bombayduck $(10.345 \%)$ formed the major contributors with an average contribution of more than $10 \%$. Rest of the resources, on average, contributed between 1 and $10 \%$ of the total catches. The yield, biomass, CPUE trajectory and yield curve can be generated for each species using catch and effort data. The representative graphs (croakers) depicting the curves are given as Fig. 2 .

The maximum sustainable yield for the resource groups was calculated and assessed for model fit, but in some cases, it was found to be weak, especially the groups having meager contribution to the total catch viz, bigjawed jumper, barracudas, billfishes, eels, halfbeaks and fullbeaks, silverbellies and unicorn cod. For these species, an alternate method was adopted. The recent median catch (last ten years) of the time series was taken as experimental MSY values for these species. The estimated MSY was compared with the recent catch (previous three-year average) to access the current exploitation status. The value ranged between $0.25 \mathrm{t}$ for unicorn cod to $1.54 \mathrm{t}$ for silverbellies. The current landings of several species are above the estimated MSY, reflecting in the $Y_{\text {curl }} / M S Y>1.0$ viz. bigjawed jumper, barracudas, billfishes, bombayduck, eels, flatfishes, 


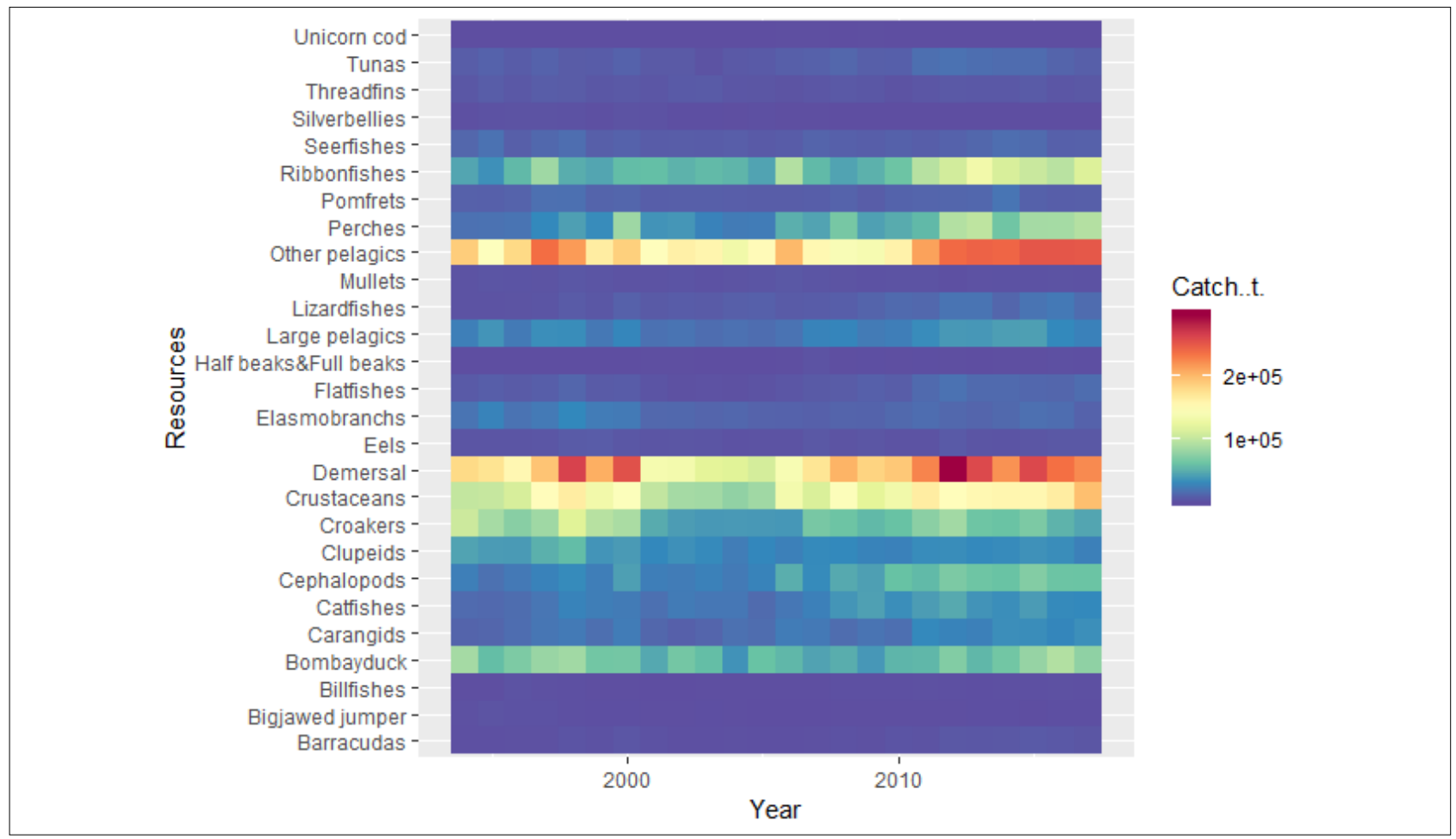

Fig. 1. Heat map showing inter-annual fluctuations in catches for major resource groups landed along the Gujarat Coast.

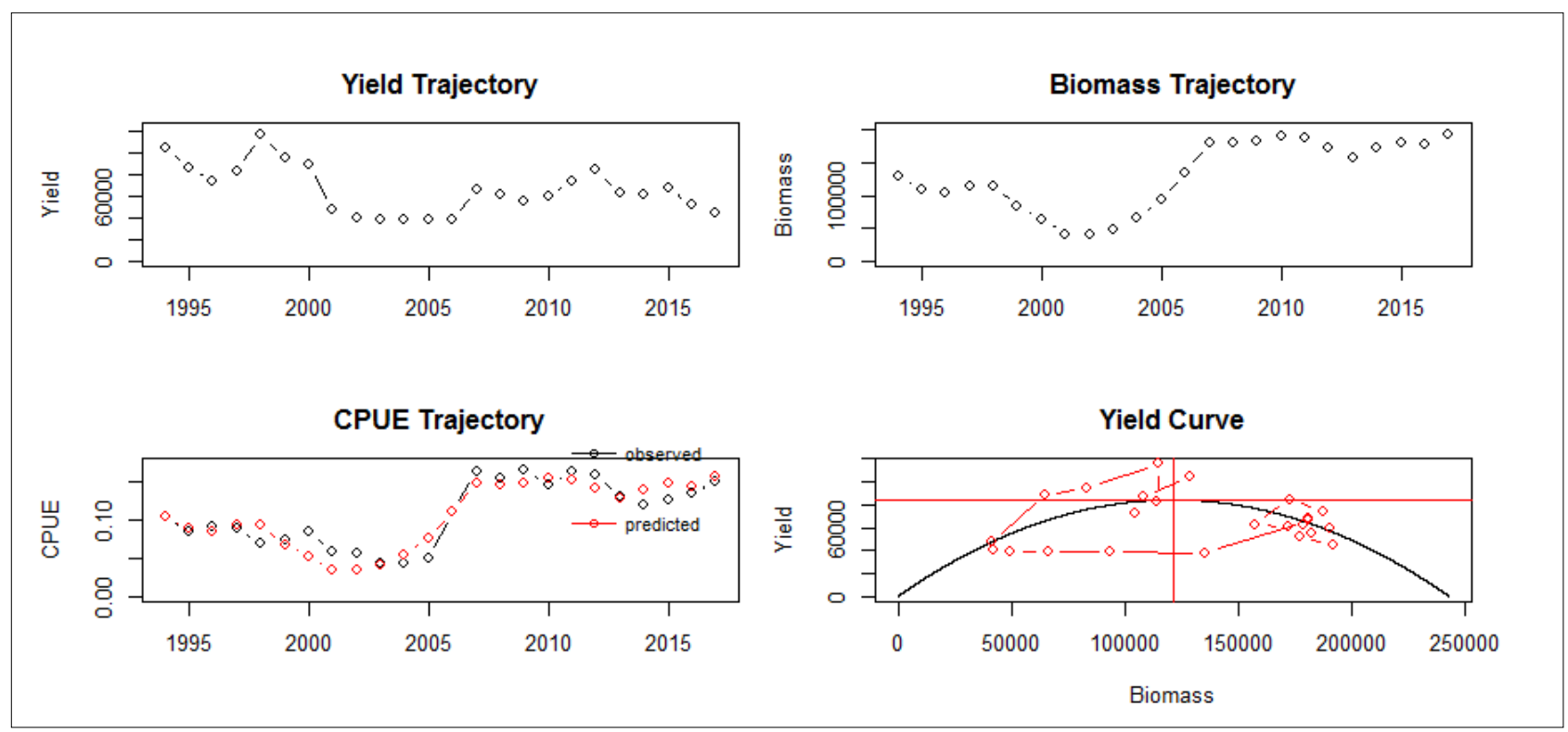

Fig. 2. The yield (t), biomass (t), CPUE (t/hr) trajectory, and yield curve generated for a representative species group (croakers) from the time series catch and effort data.

halfbeaks, fullbeaks and silverbellies. The lower $\mathrm{Y}_{\text {curl }} / \mathrm{MSY}<0.7$ was observed in the case of croakers, elasmobranchs, mullets, seerfishes, threadfins, tunas, and unicorn cod (Table 1). $Y_{\text {cur }} / M S Y$ for the broad resource group is approaching unity, but in none of the cases surpassed the value of one (Table 2). The pooled group MSY for all the species groups was estimated at 9.11 lakh tonnes. The selected resources were grouped into large pelagics, other pelagics, demersals, crustaceans, and cephalopods and a separate MSY estimate was made, which gave total MSY for different consolidated groups as 9.36 lakh tonnes, quite similar to the sum of individual estimates. The broad group-wise MSY and current yield to the MSY ratio is presented in Table 2. 
Table 1. Estimation of maximum sustainable yield/potential yield for commercial fishery species group landed at Gujarat

\begin{tabular}{|c|c|c|c|c|}
\hline SI. No. & Species/Resource group & $Y_{\text {curr }}$ & MSY & $Y_{\text {curr }} / M S Y$ \\
\hline 1 & Big-jawed jumper & 450 & $428^{*}$ & 1.05 \\
\hline 2 & Barracuda & 4526 & $3720^{*}$ & 1.22 \\
\hline 3 & Billfishes & 884 & $752^{*}$ & 1.18 \\
\hline 4 & Bombay duck & 82395 & 70113 & 1.18 \\
\hline 5 & Carangids & 31538 & 33102 & 0.95 \\
\hline 6 & Catfishes & 33543 & 44695 & 0.75 \\
\hline 7 & Cephalopods & 64572 & 74360 & 0.87 \\
\hline 8 & Clupeids & 30976 & 39964 & 0.78 \\
\hline 9 & Croakers & 54856 & 84263 & 0.65 \\
\hline 10 & Crustaceans & 171953 & 206651 & 0.83 \\
\hline 11 & Eels & 4033 & 3016 & 1.34 \\
\hline 12 & Elasmobranchs & 14053 & 25076 & 0.56 \\
\hline 13 & Flatfishes & 13281 & 12052 & 1.10 \\
\hline 14 & Halfbeaks and Full beaks & 615 & $435^{*}$ & 1.41 \\
\hline 15 & Lizardfishes & 18651 & 18117 & 1.03 \\
\hline 16 & Mullets & 1795 & 3056 & 0.59 \\
\hline 17 & Perches & 88408 & 89324 & 0.99 \\
\hline 18 & Pomfrets & 8670 & 12168 & 0.71 \\
\hline 19 & Ribbonfishes & 104266 & 142585 & 0.73 \\
\hline 20 & Seerfishes & 10973 & 20955 & 0.52 \\
\hline 21 & Silverbellies & 116 & $75^{\star}$ & 1.55 \\
\hline 22 & Threadfins & 4589 & 7499 & 0.61 \\
\hline 23 & Tunas & 11163 & 18645 & 0.60 \\
\hline 24 & Unicorn cod & 11 & $44^{*}$ & 0.25 \\
\hline
\end{tabular}

*The estimates arrive as median catch of the last ten years from time-series data $Y_{\text {curr }}$ is the average catch in the previous three years

Table 2. Estimation of maximum sustainable yield/potential yield for broad fishery group landed at Gujarat

\begin{tabular}{|c|c|c|c|c|}
\hline SI. No. & Resource group & $Y_{\text {curr }}$ & MSY & $Y_{\text {curr }} / M S Y$ \\
\hline 1 & Cephalopods & 64572 & 74360 & 0.87 \\
\hline 2 & Crustaceans & 171953 & 206651 & 0.83 \\
\hline 3 & Demersal fishes & 239507 & 309162 & 0.77 \\
\hline 4 & Large pelagic fishes & 32749 & 41697 & 0.78 \\
\hline 5 & Other Pelagics & 251045 & 304668 & 0.82 \\
\hline
\end{tabular}

\section{Discussion}

The present fish landing in the State of Gujarat is 7.80 lakh tonnes, which have registered an increase of $46.34 \%$ since 1994 (5.33 lakh tonnes). The common effort in terms of total fishing hours has also recorded an escalation by $25.46 \%$ from the figures of 1994 (NMLRDC, Kochi). Also, there has been a shift in the relative contribution of the different species to the total landings with several species recording increase in catches like crustaceans, ribbonfishes, cephalopods, etc., whereas resources like croakers registered a decline. The change in species composition may be a function of changing abundance, technological changes, the relative effort of different gear, shift in fishing ground, or market-driven demands propelling targeting harvest of selected resources. The rapid increase in the quantum of fish landings and the fishing effort spent in the backdrop to enhance the endurance and efficiency of fishing vessels warrants a measure of sustainability. In the present study, we estimated the maximum sustainable yield for the 24 resource groups using the Schaefer surplus production model using the time series catch and effort data available with NMLRDC, Kochi as input. The data available with NMLRDC has been used on numerous occasions as an input in surplus production model to work out potential yield and optimum fleet size for the different fishery of the country (Balan and Sathianandan, 2007; Sathianandan et al., 2008; Sathianandan and Jayasankar, 2009; Najmudeen et al., 2014; Sreekanth et al., 2015).

Nevertheless, it is worth mentioning that in tropical fisheries like ours, several resources are harvested by a single gear, and also single resource is harvested from multiple gears. The gears may vary with the mode of operation and duration of operation with changing catchability for a given resource. In such a scenario, the raw fishing effort or simple weighted effort in total fishing hours as input is not justifiable and recommended. The standardized fishing effort for a given species, which is the relative contribution of resources in different gears with co-occurring species and its variance over the study period (detail procedure laid out in methods section; Varghese at el., 2020 ) is used as input in the model.

The estimate of MSY for most of the resource groups was quite good, barring few species where the model fit was found to be poor viz., bigjawed jumper, barracudas, billfishes, eels, halfbeaks and fullbeaks, silverbellies and unicorn cod. On visualization, it was observed that for all these groups, the average contribution over the study period to the total landings was very less $(<1.0 \%)$, and from a few of them, the data for some years are very less or absent. It seems that the standardization protocol adopted may not be apt for a species with such low contribution to total catch or having a missing value of the catch in time series. In these resource groups, an alternate approach laid for data-limited fisheries were adopted. The median catch in a time series has been in use to set catch limits in fisheries with a poor database (Carruthers et al., 2014). The median catch for the last ten years of a time series data has been proposed as MSY for the groups, as mentioned earlier. The reason behind restricting to only the recent ten years is to capture the latest trends and also to arrive at a reasonable estimate in recently developed fisheries, e.g., barracuda, which were earlier not a target species. In the case of newly emerging fisheries, the use of the entire time series may lead to a large underestimation of reference yield. 
The estimated MSY when compared with the present catch (last three averages) as $\mathrm{Y}_{\text {cur }} / \mathrm{MSY}$ has yielded values in the range of 0.25 to 1.55 . Species like bigjawed jumper, barracudas, billfishes, eels, halfbeaks, and fullbeaks and silverbellies that are presently exploited above the level of estimated MSY ( $\left.\mathrm{Y}_{\text {cur }}\right) \mathrm{MSY}$ $>1.0$ ) need closer monitoring. Since the contribution of these groups to the total catch is very less $(<1.0 \%)$, the chances of error in estimation are high. Similar is the case with unicorn cod where the $\mathrm{Y}_{\text {cur }} / \mathrm{MSY}$ is only 0.25 . A more detailed cohort-based study for this group is advisable to capture the significance of stock status. Furthermore, frequent assessment and baseline estimates of biomass and potential yield are required to avoid irreversible damage to these resources. In many species groups like elasmobranchs, croakers, and threadfins, the $\mathrm{Y}_{\text {cur }} / \mathrm{MSY}(<1.0)$ is indicative of the possibility of fisheries expansion. But while doing so, it should be kept in mind that these groups are species complex with higher -diversity. Many species within the group are of conservation concern, especially in elasmobranchs. Though, as a group, they are underutilized, some species may be facing rapid decline. The large-sized croakers like Otolithoides sp., and Protonibea sp., are known to have declined in the region. In such cases, species wise assessment is recommended if the expansion of fisheries is to be executed.

Awareness among fishers on the exploitation of endangered elasmobranchs and release back in case of accidental capture and development of species-specific bycatch reduction devices can support the expansion of fisheries without any detrimental effect on the protected species. Depth decomposed estimation of potential yield could also be an excellent future endeavor as resource distribution is mostly depth stratified, and the effort over the years has slowly but surely shifted to deeper waters. The increasing catch rate of the resource groups from deeper water may lead to a higher overall MSY value for the entire group. In contrast, the coastal species of the group, which has been the principal target in the past, but presently in the recovery or depleted condition. The increasing catch of the former species in recent years are the reason behind the high abundance index for the entire group, whereas the present status of coastal species is uncertain. Similar could be the situation with other groups also. Conventional resource like bombayduck is fished marginally over the potential yield. Hence, further intensification of the fishery for the resource is not advisable, whereas a marginal increase in effort for ribbonfishes $\left(Y_{\text {cur }} / \mathrm{MSY}=0.73\right)$ is still possible. With the emergence of multi-day fisheries and incentives from the Union Government for deep-sea longlining (in the form of subsidy scheme for conversion to longliners) will gear-up the exploitation of underutilized oceanic fisheries $\left(\mathrm{Y}_{\text {curr }} / \mathrm{MSY}=0.60\right)$ which can be explored for enhanced production. On the broader group scale, the present catch of 7.80 lakh tonnes is below the estimated potential yield of more than 9.11 lakh tonnes, offering a scope for the increase in production but with species-specific fisheries expansion. The present study provides a preliminary estimate of the potential yield, which can be upgraded using more decomposed catch data and depth categories. The forecast can also be cross-validated with alternate methods viz., primary productivity based, or tropho-dynamic approach as done in the national estimate of potential fishery yield by (DAHDF, 2011).

\section{Acknowledgements}

Authors are thankful to Dr. A. Gopalakrishnan, Director, ICARCMFRI, and Dr. T.V. Sathianandan, Head, Fishery Resources Assessment Division, ICAR-CMFRI, Cochin for the encouragement and support during the study period. The authors would like to thank Dr. Eldho Varghese, Scientist, ICAR-CMFRI for the technical inputs provided for fishing effort standardization during the study in the region.

\section{References}

Balan, K. and T. V. Sathianandan. 2007. As assessment of the ring seine fishery in Kerala through surplus production model. Indian. J. Fish., 52 (2): 135-140.

Carruthers, T. R., A. E. Punt, C. J. Walters, A. MacCall, M. K. McAllister, E. J. Dick and J. Cope. 2014. Evaluating methods for setting catch limits in data-limited fisheries. Fish. Res., 153: 48-68.

CMFRI. 1981. All India census of marine fishermen, craft, and gear:1980. Mar. Fish. Inform. Ser. T\& E Serv., 30: 32.

CMFRI, Kochi. 2019. CMFRI Annual Report 2018-19. Technical Report. CMFRI, Kochi.

DAHDF and CMFRI. 2006. Marine Fisheries Census 2010 Part-III (10) Gujarat. Department of Animal Husbandry Dairying and Fisheries \& Central marine Fisheries Research Institute, 259p.

DAHDF and CMFRI. 2012. Marine Fisheries Census, 2010 Gujarat. Department of Animal Husbandry Dairying and Fisheries \& Central marine Fisheries Research Institute, 218p.

DAHDF. 2011. Report of the working group for revalidating the potential of the fishery resources in the Indian EEZ. Department of Animal Husbandry Dairying and Fisheries, New Delhi, $69 \mathrm{p}$.

FAO. 2018. The State of the world fisheries and aquaculture. Food and Agriculture Organisation, Rome, 210 p.

Jones, S. and S. K. Banerji. 1973. A review of the living resources of the Central Indian Ocean. Proc. Symp. Living Resources of seas around India. CMFRI spl. Pub., p. 1-17.

Mitra, G. N., 1973. Method of estimation of fish abundance in the Indian Ocean and steps to be taken for the management of commercial fisheries. Proc. Symp. Living Resources of seas around India. CMFRI spl. Pub., p. 1-17.

Najmudeen, T. M., T.V. Sathianandan and P. U. Zacharia. 2014. Fleet optimization of trawl fishery along the southwest coast of India using surplus production model. J. Mar. Biol. Ass. India, 56(2): 74-80.

Prager, M. H. 1994. A suite of extension to the non-equilibrium surplus production model. Fish. B. NOAA, 92(2): 374-389.

Prasad, R. R., S. K. Banerii and R. Nair. 1970. A quantitative assessment of the potential fishery resources of the Indian ocean and adjacent sea. Indian J. Anim. Sci., 40 (1): 73-98.

Sathianandan, T. V. and J. Jayasankar. 2009. Managing marine fishery in Kerala through simulation using surplus production model, genetic algorithm, and spectral methods. Indian J. Fish., 56 (3): 163-168.

Sathianandan, T. V., J. Jayasankar, E. Vivekanandan, R. Narayana Kumar and N. G. K. Pillai. 2008. Estimates on the potential yield and maximum sustainable fleet size for the marine fisheries in Kerala. J. Mar. Biol. Ass. India, 50 (2): 196-201.

Sparre, P. and S. C. Venema. 1998. Introduction to the tropical fish stock assessmentpart1: Manual. FAO fisheries technical paper 306/1. FAO, Rome, 407p.

Sreekanth, G. B., P. U. Zacharia, T. V. Sathianandan, S. Thomas, N. Manjulekshmi and N. P. Singh. 2015. Combining surplus production and spectral models to define fishery management advisory-a case study using the threadfinbream fishery along Kerala coast. Indian. J. Fish., 62 (1): 41-45.

Varghese, E. T. V. Sathiananadan, J. Jayasankar, Somy Kuriakose, K. G. Mini and M. Muktha. 2020. Bayesian State- space Implementation of Schaefer Production for Assessment of stock status for multi-gear fishery. J. Ind. Soc. Agr. Stat., 74(1): 35-42. 